\title{
Periodontal Tissue Status among Mental Retardation Patients with Fixed Prosthodontic Appliances
}

\author{
Mohammed M. A. Abdullah Al-Abdaly ${ }^{*}$, Abdulaziz Mushabbab Abu Qahas ${ }^{2}$, \\ Abdullah Mushabbab Ali Honbos ${ }^{3}$, Abdulrahman Ahmed Abdullah Alshehri ${ }^{3}$ \\ ${ }^{1}$ Periodontics Department, College of Dentistry, King Khalid University, Abha, Saudi Arabia \\ ${ }^{2}$ Ministry of Health, Bisha, Saudi Arabia \\ ${ }^{3}$ College of Dentistry, King Khalid University, Abha, Saudi Arabia \\ Email: *malabdaly20@gmail.com
}

How to cite this paper: Al-Abdaly, M.M.A.A., Qahas, A.M.A., Honbos, A.M.A. and Alshehri, A.A.A. (2018) Periodontal Tissue Status among Mental Retardation Patients with Fixed Prosthodontic Appliances. International Journal of Clinical Medicine, 9, 49-58.

https://doi.org/10.4236/ijcm.2018.91006

Received: December 28, 2017

Accepted: January 21, 2018

Published: January 24, 2018

Copyright (c) 2018 by authors and Scientific Research Publishing Inc. This work is licensed under the Creative Commons Attribution International License (CC BY 4.0).

http://creativecommons.org/licenses/by/4.0/

\begin{abstract}
Background: The mental, physical and social impediments cause limitation of chances in normal life as an equal level with others of the community; particularly in relation to maintain good oral hygiene and periodontal health among the disabled patients who were receiving fixed partial denture. So the present study was performed to evaluate the periodontal tissue status among mental retardation patients with fixed prosthodontic appliances. Subjects and $\mathrm{Me}-$ thods: A total of 400 patients between the ages 18 and 50 years were clinically selected from outpatient clinics, college of dentistry, King Khalid University and rehabilitation center in Abha city, Saudi Arabia. They were divided into two equal groups as the following: group I: Two hundred mental retardation patients without fixed prosthodontic appliances (control group) and, group II: Two hundred mental retardation patients had fixed prosthodontic appliances for at least a year ago. A complete periodontal clinical examination was performed and the following indices were recorded: plaque index (PLI), gingival index (GI), and clinical attachment loss (CAL). All data was recorded and analyzed by ANOVA test. Results: The clinical results of the present study confirmed the relationship among the mental retardation, fixed prosthodontic appliances and destruction of periodontal tissues. It has been found that the severity of periodontal disease increases among the study group compared to the control group. Statistically significant differences were found in PLI, GI and CAL in the comparison between group I and II $(p<0.05)$. Conclusion: There was a negative relationship between mental retardation with a status of periodontal tissues and oral hygiene among the patients under fixed prosthodontic management.
\end{abstract}




\section{Keywords}

Fixed Prosthodontic Appliances, Mental Retardation, Periodontal Tissue Status

\section{Introduction}

Periodontal disease is defined as a multi-factorial chronic infection, which causes destruction of tooth supporting tissues. Generally, it is widespread among adult patients. Therefore there are some systemic diseases which can cause progression of periodontal disease, and according to some studies, periodontal diseases don't affect all persons or teeth at the same time or by the same method. Consequently there is an interpersonal variation [1] [2].

A prosthodontic management is the replacement of missing teeth so as to an esthetic and a functional rehabilitation of the patient's mouth. The success of this treatment depends on its resistance and its biological effect on periodontal tissues and there were several researches that displayed increased plaque accumulation on prosthodontic appliances which have an unfavorable effect on periodontal tissue. Therefore periodontal disease is considered as a common complication of fixed partial dentures [3]-[8].

Mental retardation is a defect of mental capacity tests and causes restricted daily living capacity with weak social communication skills [9]. According to many studies the periodontal and oral health among mentally retarded persons was lower than that of normal persons and when periodontal disease appears among these patients with one of other systemic diseases, this leads to periodontal destruction without knowing the cause [10]-[16].

The oral hygiene information of the disabled people oral hygiene was rare and was based on the evaluation of a small number of people with vastly various ages, particularly who received fixed partial denture. Seymour and Greeley et al. as well as other investigators observed that there was a significant effect of disability on periodontal tissues [17]-[22]. In addition, Svatum and Gjermo detected that there was a decrease in periodontal health status with the increase of age and a high degree of mental deficiency of disabled patients [23]. According to other studies that were done on the oral hygiene status of the handicapped patients, there was a high spread progression of gingival and periodontal disease, a large number of increased missing teeth, high susceptibility to traumatic injuries in the mouth, increased tooth wear and poor oral and denture hygiene [24] [25] [26] [27] [28]. To depend on our knowledge, there is no published study about the periodontal tissue status among mental retardation patients with fixed prosthodontic appliances in Aseer region, Saudi Arabia. The aim of this cross-sectional study was to evaluate the periodontal tissue status among mental retardation patients with fixed prosthodontic appliances in Aseer region, Saudi Arabia. 


\section{Subjects and Methods}

A cross-sectional study was done from April 2017 to October 2017. 400 moderate mental retardation patients, aged between 18 and 50 years old, were selected from outpatient clinics, College of Dentistry, King Khalid University and rehabilitation center in Abha city, Saudi Arabia. They were divided into two groups as the following: Group I: Two hundred moderate mental retardation patients without fixed prosthodontic appliances (control group) and, group II: Two hundred moderate mental retardation patients had fixed prosthodontic appliances for at least a year ago (Figures 1-3). A complete periodontal clinical examination was performed and the following indices were recorded: Plaque index (PLI) [29], gingival index (GI) [30], and clinical attachment loss (CAL).

All participants in the present study were without systemic diseases and they had not received any periodontal and antibiotic therapy for at least six months before the study was conducted. The consent of all participants was obtained to meet the protocol of the scientific college of dentistry, King Khalid University. The results of the present study were recorded, tabulated and analyzed by using SPSS version 23and by conducting ANOVA test.

\section{Results}

Table 1 and Figure 4 of clinical examination show the clinical findings of the present study. In Group II, the mean and standard deviation $( \pm \mathrm{SD})$ of plaque index (PLI) is $2.43 \pm 0.6$, which coincides with the presence of plaque at gingival margin, and the mean and standard deviation $( \pm \mathrm{SD})$ of gingival index (GI) is $2.19 \pm 0.4$ furthermore the mean and standard deviation $( \pm \mathrm{SD})$ of clinical attachment loss (CAL) was is $5.33 \pm 0.7$. In Group I (control group), the mean and standard deviation $( \pm \mathrm{SD}$ ) of PLI was is $1.82 \pm 0.43$, and the mean and standard deviation $( \pm \mathrm{SD})$ of GI is $1.61 \pm 0.52$ also the mean and standard deviation $( \pm \mathrm{SD})$ of clinical attachment loss (CAL) is $3.22 \pm 0.71$.

Most patients in the group study displayed moderate plaque to abundant levels compared to mild to moderate plaque in the control group, whereas all patients of the study group were diagnosed with moderate to severe plaque induced gingivitis compared to mild to moderate plaque induced gingivitis in the control group. On the other hand, most patients in group study were diagnosed with moderate to severe chronic periodontitis compared to mild to moderate chronic periodontitis in the control group. In the present study there was highly significance differences in PLI plaque index (PLI), gingival index (GI) and clinical attachment loss (CAL) between Group I and Group II ( $p=000)$ where PLI, CI and CAL were more in Group II compared to Group I.

\section{Discussion}

Oral care and its quality participate in general health, which must be excellent and right [31]. The oral care of the disabled may be neglected because of their 


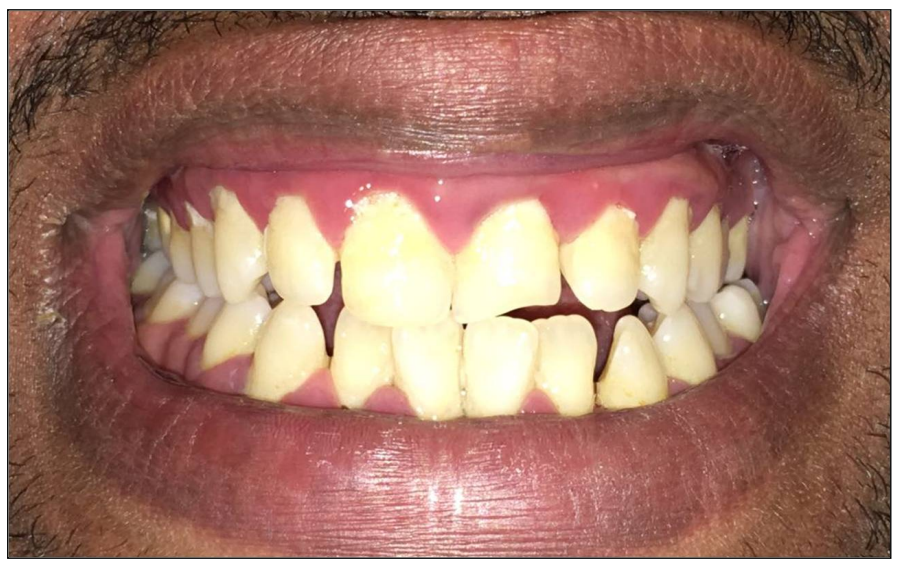

Figure 1. Periodontal changes of control case.

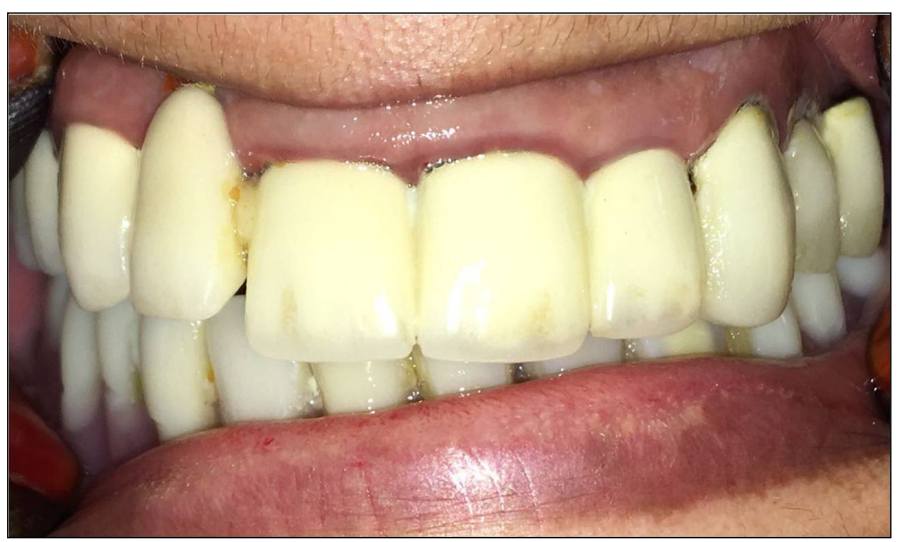

Figure 2. Periodontal changes with anterior fixed appliance.

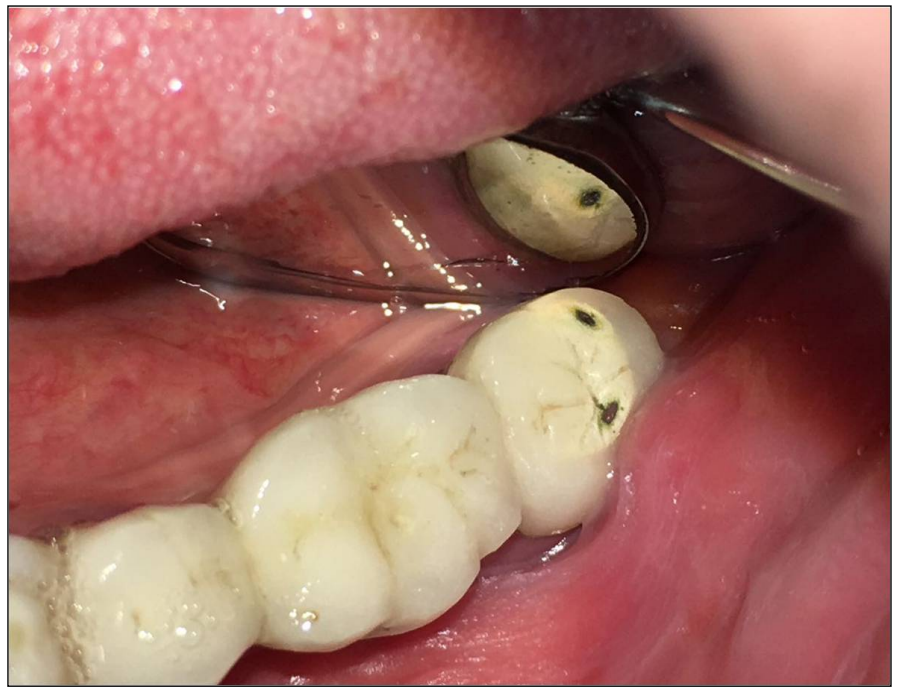

Figure 3. Periodontal changes with posterior fixed appliance.

disability, or their restricted access to oral care [32]. Patients with disabilities worth the same chances for oral and dental services as normal patients, in particular the disabled patients who were receiving fixed partial denture. So the aim 


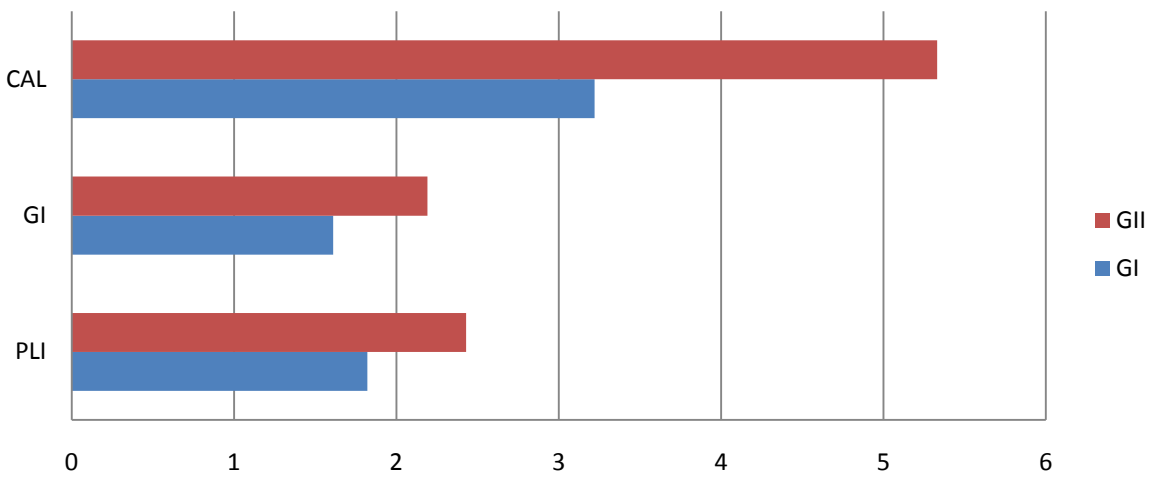

Figure 4. Clinical findings.

Table 1. Clinical findings.

\begin{tabular}{ccc}
\hline Clinical parameters & GI & GII \\
\hline PLI & $1.82 \pm 0.43$ & $2.43 \pm 0.6$ \\
GI & $1.61 \pm 0.52$ & $2.19 \pm 0.4$ \\
CAL & $3.22 \pm 0.71$ & $5.33 \pm 0.7$ \\
\hline
\end{tabular}

of the current study was to evaluate the periodontal tissue status among mental retardation patients with fixed prosthodontic appliances.

Periodontal disease was found to be common among rehabilitation center patients in Abha city due to their inability to perception the procedures of oral health prevention. Moreover, as is known that the disabled patients are more susceptible to progression of periodontal disease compared to normal patients. They don't have got periodontal therapy, for these patients get inadequate oral hygiene instructions. And some of these patients breathe from their mouth, which could cause mouth dryness and increase plaque and calculus formation [33]. There are some factors of prosthodontic appliances like poor marginal edges adaptation and bad design of their contours which linked with inflammatory periodontal disease [34].

In the study of Ozgul et al. on one hundred and five patients with mental retardation (MR), there were statistically significant increase for the severity of MR and increase in clinical periodontal indices due to their bad oral hygiene. And it may aggravated by intensity of MR [35].

This study agrees with the results of the present study that there were significance differences in plaque index (PLI), gingival index (GI) and clinical attachment loss (CAL) between group I and group II $(\mathrm{p}<0.005)$ where PLI, CI and CAL were more in group I compared to group II. Moreover in another study of patients with Down syndrome, there was greater susceptibility to periodontal disease due difficulty in their oral hygiene and deficiency in their immunity against dental biofilm and periodontal pathogenic bacteria [36].

Furthermore and according to Gerreth et al. on patients with systemic disorders, MR, Immunological factors, bad oral hygiene and greater of plaque and cal- 
culus were considered risk factors for periodontal diseases. There was increase in plaque index 1.08 and the gingival index was 1.06 [37]. In the study carried out in Polonia to assess the gingival and oral status of mental retardation (MR) children and adolescent, there were plaque index of 1.33 and a gingival index of 1.67. The study results agree with the results of the present study and emphasize the results of other researches of bad oral hygiene and increased incidence of periodontal disease among the disability patients [38].

In Indian study on 750 teenagers between 14 - 17 year olds in five groups, one hundred and fifty intellectually disabled, 150 visually impaired, 150 physically handicapped, 150 dumb and 150 deaf and 150 control group were examined. There was increase in bad oral hygiene, PLI and incidence of periodontal disease in the intellectually disabled group compared to control group [39]. And in 2004, Carvalho and Araújo have declared that periodontal disease is the most pathological changes in the oral mucosa among mentally handicapped patients due to their bad oral hygiene and the inability in performing the mechanical removal of bacterial plaque correctly [40].

This study agrees with the results of Nigerian study done on mentally handicapped school children to assess their periodontal health. Most patients in group study displayed moderate plaque to abundant levels compared to mild to moderate plaque in the control group. The study group was diagnosed with moderate to severe gingivitis compared mild to moderate gingivitis in the control group. On the other hand, most patients in group study were diagnosed with moderate to severe chronic periodontitis compared to mild to moderate chronic periodontitis in the control group. All patients needed oral hygiene care and none of them had a healthy periodontium [41].

Moreover, different materials may be used for fixed prosthodontic appliances. In the present study, there were no significance differences in all clinical parameters among the mental retardation patients with fixed prosthodontic appliances made of different materials. These findings agree with the results of previous study that were carried out on different dental materials [42]. On the other hand, in the present study and according to the placement of the fixed prosthodontic appliance in upper or in the lower jaw, there were no differences in the effect of the fixed prosthodontic appliance on periodontal tissues, but these differences revealed among elderly patients more evidently than young patients. It may be the decrease in their host defense and nutritional deficiency.

A key limitation to this study was the lack in the studies on clinical evaluation of periodontal status among mental retardation patients being treated to replacement of missing teeth with fixed partial dentures in Saudi Arabia. Moreover this study was the first study in Aseer region. Second, there were difficulties during clinical examination and we depended on the patients companions, especially in the case history assessment and also the patients in the present study were in poor cooperation and attention, which affected the periodontal and oral hygiene status of the patients. Therefore, periodontal disease was more common among mental retardation patients compared to the normal persons. Finally, the 
appointments were short and there was delay in the patient visit sometimes.

\section{Conclusion}

Our study demonstrated that the severity of periodontal diseases of the mental retardation patients who received fixed prosthodontic appliances was higher than the control group with a decline in oral hygiene status. Therefore, an educational program for patients, their parents and caregivers should be applied to improve their periodontal status.

\section{Acknowledgements}

The authors would like to thank the rehabilitation center staff in Abha city, Saudi Arabia for their generous helping to accomplish this study.

\section{Conflicts of Interest}

There are no conflicts of interest.

\section{References}

[1] Shimazaki, Y., Shirota, T., Uchida, K., Yonemoto, K., Kiyohara, Y., Iida, M., Saito, T. and Yamashita, Y. (2008) Intake of Dairy Products and Periodontal Disease: The Hisayama Study. Journal of Periodontology, 79, 131-137. https://doi.org/10.1902/jop.2008.070202

[2] Nualart-Grollmus, Z.C., Morales Chávez, M.C. and Silvestre Donat, F.J. (2007) Periodontal Disease Associates to Systemic Genetic Disorders. Medicina Oral Patologia Oral y Cirugia Bucal, 12, e211-e215.

[3] Bragger, U., Aeschlimann, S., Burgin, W., Hammerle, C.H. and Lang, N.P. (2001) Biological and Technical Complications and Failures with Fixed Partial Dentures (FPD) on Implants and Teeth after Four to Five Years of Function. Clinical Oral Implants Research, 12, 26. https://doi.org/10.1034/j.1600-0501.2001.012001026.x

[4] Hammerle, C.H., Ungerer, M.C., Fantoni, P.C., Bragger, U., Burgin, W., Lang, N.P. (2000) Long-Term Analysis of Biologic and Technical Aspects of Fixed Partial Dentures with Cantilevers. The International Journal of Prosthodontics, 13, 409.

[5] Karlsson, S. (1989) Failures and Length of Service in Fixed Prosthodontics after Long-Term Function. A Longitudinal Clinical Study. Swedish Dental Journal, 13, 185.

[6] Leempoel, P.J., Eschen, S., De Haan, A.F. and Van't Hof, M.A. (1985) An Evaluation of Crowns and Bridges in a General Dental Practice. Journal of Oral Rehabilitation, 12, 515. https://doi.org/10.1111/j.1365-2842.1985.tb01299.x

[7] Valderhaug, J. (1991) A 15-Year Clinical Evaluation of Fixed Prosthodontics. Acta Odontologica Scandinavica, 49, 35. https://doi.org/10.3109/00016359109041138

[8] Valderhaug, J. (1980) Periodontal Conditions and Carious Lesions Following the Insertion of Fixed Prostheses: A 10-Year Follow-Up Study. International Dental Journal, 30, 296.

[9] El-Hazmi, M.A., Al-Swailem, A.A., Al-Mosa, N.A. and AlJarallah, A.A. (2003) Prevalence of Mental Retardation among Children in Saudi Arabia. The Eastern Mediterranean Health Journal, 9, 6-11.

[10] Choi, N.K. and Yang, K.H. (2003) A Study on the Dental Disease of the Handi- 
capped. Journal of Dentistry for Children (Chic), 70, 153-158.

[11] Desai, M., Messer, L.B. and Calache, H.A. (2001) Study of the Dental Treatment Needs of Children with Disabilities in Melbourne, Australia. Australian Dental Journal, 46, 41-50. https://doi.org/10.1111/j.1834-7819.2001.tb00273.x

[12] Kozak, R. (2004) Dental and Periodontal Status and Treatment Needs of Institutionalized Mentally Retarded Children from the Province of West Pomerania. Annales Academiae Medicae Stetinensis, 50, 149-156.

[13] Bamjee, Y., Chikte, U.M. and Cleaton-Jones, P.E. (199) Assessment of Periodontal Status and Treatment Needs of a Disabled Population Using the CPITN. SADJ, 54, 413-417.

[14] Escribano Hernández, A., Hernández Corral, T., Ruiz-Martín, E. and Porteros Sánchez, J.A. (2007) Results of a Dental Care Protocol for Mentally Handicapped Patients Set in a Primary Health Care Area in Spain. Medicina Oral Patologia Oral $y$ Cirugia Bucal, 12, 492-495.

[15] Simon, E.N., Matee, M.I. and Scheutz, F. (2008) Oral Health Status of Handicapped Primary School Pupils in Dares Salaam, Tanzania. East African Medical Journal, 85, 113-117.

[16] Sollecito, T.P., Sullivan, K.E., Pinto, A., Stewart, J. and Korostof, J. (2005) Systemic Conditions Associated with Periodontitis in Childhood and Adolescence. A Review of Diagnostic Possibilities. Medicina Oral, Patologia Oral y Cirugia Bucal, 10, 142-150.

[17] Johnson, C.D., Matt, M.K., Dennison, D., Brown, R.S. and Koh, S. (1996) Preventing Factitious Gingival Injury in an Autistic Patient. The Journal of the American Dental Association, 127, 244-247. https://doi.org/10.14219/jada.archive.1996.0176

[18] Seymour, R.A., Thomason, J.M. and Ellis, J.S. (1996) The Pathogenesis of Drug-Induced Gingival Overgrowth. Journal of Clinical Periodontology, 23, 165-175. https://doi.org/10.1111/j.1600-051X.1996.tb02072.x

[19] Greeley, C.B., Goldstein, P.A. and Forrester, D.J. (1976) Oral Manifestations in a Group of Blind Students. ASDC Journal of Dentistry for Children, 43, 39-41.

[20] Shaw, L., Maclaurin, E.T. and Foster, T.D. (1986) Dental Study of Handicapped Children Attending Special Schools in Birmingham, UK. Community Dentistry and Oral Epidemiology, 14, 24-27. https://doi.org/10.1111/j.1600-0528.1986.tb01488.x

[21] Nunn, J.H. and Murray, J.J. (1987) The Dental Health of Handicapped Children in Newcastle and Northumberland. British Dental Journal, 162, 9-14. https://doi.org/10.1038/sj.bdj.4806011

[22] Lindh, J., karring, T. and Lang, N. (2003) Clinical Periodontology and Implant Dentistry. 4th Edition, Denmark, Munksgard, 52.

[23] Svatun, B. and Gjermo, P. (1978) Oral Hygiene, Periodontal Health and Need for Periodontal Treatment among Institutionalized Mentally Subnormal Persons in Norway. Acta Odontologica Scandinavica, 36, 89-95. https://doi.org/10.3109/00016357809027571

[24] Francis, J.R., Stevenson, D.R. and Palmer, J.D. (1991) Dental Health and Dental Care Requirements for Young Handicapped Adults in Wessex. Community Dent Health, 8, 131-137.

[25] Hogan, J.I. and White, T. (1982) Dental Health Education in an Adult Handicapped Centre. Dental Update, 9, 283-284.

[26] Kendall, N.P. (1992) Differences in Dental Health Observed within a Group of Non-Institutionalised Mentally Handicapped Adults Attending Day Centres. 
Community Dental Health, 9, 31-38.

[27] Shaw, M.J., Shaw, L. and Foster, T.D. (1990) The Oral Health in Different Groups of Adults with Mental Handicaps Attending Birmingham (UK) Adult Training Centres. Community Dental Health, 7, 135-141.

[28] Hinchliffe, J.E., Fairpo, C.G. and Curzon, M.E. (1988) The Dental Condition of Mentally Handicapped Adults Attending Adult Training Centres in Hull. Community Dental Health, 5, 151-162.

[29] Silness, J. and Loe, H. (1964) Periodontal Disease in Pregnancy. II. Correlation between Oral Hygiene and Periodontal Condition. Acta Odontologica Scandinavica, 22, 121-135.

[30] Loe, H. and Silness, J. (1963) Periodontal Disease in Pregnancy. I. Prevalence and Severity. Acta Odontologica Scandinavica, 21, 533-551.

[31] Clark, C.A. and Vanek, E.P. (1984) Meeting the Health Care Needs of People with Limited Access to Care. Journal of Dental Education, 48, 213-216.

[32] Kumar, S., Sharma, J., Duraiswamy, P. and Kulkarni, S. (2009) Determinants for Oral Hygiene and Periodontal Status among Mentally Disabled Children and Adolescents. Journal of Indian Society of Pedodontics and Preventive Dentistry, 27, 151-157. https://doi.org/10.4103/0970-4388.57095

[33] Barnett, M.L., Press, K.P., Friedman, D. and Sonnenberg, E.M. (1986) The Prevalence of Periodontitis and Dental Caries in a Down's Syndrome Population. Journal of Periodontology, 57, 288-293. https://doi.org/10.1902/jop.1986.57.5.288

[34] Knoernschild, K.L. and Campbell, S.D. (2000) Periodontal Tissue Responses after Insertion of Artificial Crowns and Fixed Partial Dentures. Journal of Prosthetic Dentistry, 84, 492. https://doi.org/10.1067/mpr.2000.110262

[35] Ozgul, O., Dursun, E., Ozgul, B.M., Kartal, Y., Coskunses, F.M., Kocyigit, I.D. and Tözüm, T.F. (2014) The Impact of Handicap Severity on Oral and Periodontal Status of Patients with Mental Retardation. The Journal of Contemporary Dental Practice, 15, 218-222. https://doi.org/10.5005/jp-journals-10024-1518

[36] Yoshihara, T., Morinushi, T., Kiniuo, S. and Yamasaki, Y. (2005) Effect of Periodic Preventive Care on the Progression of Periodontal Disease in Young with Down's Syndrome. Journal of Clinical Periodontology, 32, 556-560. https://doi.org/10.1111/j.1600-051X.2005.00712.x

[37] Gerreth, K. and Borysewicz-Lewicka, M. (2009) Epidemiological Evaluation of Gingivitis in Special-Care Schoolchildren. Medycyna Wieku Rozwojowego, 13, 283-291.

[38] Shanbhog, R., Raju, V. and Nandlal, B. (2014) Correlation of Oral Health Status of Socially Handicapped Children with Their Oral Heath Knowledge, Attitude, and Practices from India. Journal of Natural Science, Biology and Medicine, 5, 101-107. https://doi.org/10.4103/0976-9668.127297

[39] Ameer, N., Palaparthi, R., Neerudu, M., Palakuru, S.K., Singam, H.R. and Durvasula, S. (2012) Oral Hygiene and Periodontal Status of Teenagers with Special Needs in the District of Nalgonda. Journal of Indian Society of Periodontology, 16, 421-425.

[40] Carvalho, E.M.C. and Araújo, R.P.C. (2004) A Saúde Bucal em Portadores de Transtornos Mentais e Comportamentais. Pesq Bras OdontopedClinIntegr, 4, 65-75.

[41] Denloye, O.O. (1999) Periodontal Status and Treatment Needs of 12-15 Year Old Institutionalized Mentally Handicapped School Children in Ibadan, Nigeria. Odontostomatol Trop, 22, 38-40. 
[42] Tolboe, H., Isidor, F., Budtz-Jörgensen, E. and Kaaber, S. (1988) Influence of Pontic Material on Alveolar Mucosal Conditions. Scandinavian Journal of Dental Research, 96, 442 . 